\title{
Modul Pembelajaran PPKn Bermuatan Nilai Karakter Toleransi pada Kelas V Sekolah Dasar
}

\section{Gede Pait Budhi Puniatmaja1*, Ndara Tanggu Renda ${ }^{2}$}

1,2 Program Studi Pendidikan Guru Sekolah Dasar, Universitas Pendidikan Ganesha, Singaraja, Indonesia

\section{A R T I CLE I N F O}

\section{Article history:}

Received August 30, 2021

Revised September 02, 2021

Accepted October 14, 2021

Available online October 25, 2021

Kata Kunci:

Modul Pembelajaran, Nilai Karakter Toleransi

Keywords:

Learning Module, Value of Tolerance Character

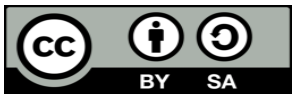

This is an open access article under the $\underline{C C}$ BY-SA license.

Copyright (C) 2021 by Author. Published by Universitas Pendidikan Ganesha.

\begin{abstract}
A B S T R A K
Kurangnya buku ajar dan penunjang untuk menyajikan pengajaran PPKn yang efektif terutama pada pelajaran tema 7 SD kelas V. Belum ada pengembangan bahan ajar yang membantu siswa untuk belajar mandiri dan menunjukkan nilai karakter toleransi. Tingkat pemhaman masing-masing siswa berbeda-beda, sehingga siswa yang memiliki kemampuan rendah akan lebih sulit memahami materi yang ada pada buku ajar. Penelitian ini bertujuan untuk menciptakan modul pembelajaran PPKn bermuatan nilai karakter toleransi pada kelas V Sekolah Dasar. Pengembangan media dalam penelitian menggunakan model ADDIE. Subjek pada penelitian ini yaitu 2 orang ahli materi, 2 orang ahli media dan desain, 2 orang praktisi Metode pengumpulan data penelitian ini menggunakan metode kuisioner dan instrumen rating scale. Teknik analisis data menggunakan analisis data statistik deskriptif kualitatif dan statistik deskriptif kuantitatif. Hasil penelitian ini yaitu hasil bahwa persentase yang diperoleh dari segi materi secara keseluruhan yaitu 96,66\%. Hasil persentase dari ahli materi pembelajaran berada pada rentangan 90-100 dengan kualifikasi sangat baik dan tidak perlu direvisi. Hasil perhitungan persentase uji validitas dari segi media pembelajaran secara keseluruhan yaitu 88,88\%. Hasil persentase dari ahli media pembelajaran berada pada rentangan 90-100 dengan kualifikasi sangat baik dan tidak perlu direvisi. Sementara itu, dari uji praktisi menyatakan bahwa modul pembelajaran ada pada kualifikasi sangat baik dengan persentase keseluruhan yaitu 94,5\%. Jadi, modul pembelajaran PPKn bermuatan nilai karakter toleransi layak untuk digunakan dalam pembelajaran. Implikasi penelitian ini yaitu modul pembelajaran PPKn bermuatan nilai karakter toleransi dapat membantu siswa dalam proses pembelajaran.
\end{abstract}

\section{A B S T R A C T}

Lack of textbooks and supporting materials to provide effective PPKn teaching, especially in the 7th grade elementary school theme lessons. There has been no development of teaching materials that help students to learn independently and show the value of the character of tolerance. The level of understanding of each student is different, so students who have low abilities will find it more difficult to understand the material in the textbook. This study aims to develop Civics learning modules containing the value of the character of tolerance in class $V$ of Elementary School. Media development in research uses the ADDIE model which includes the Analyze, Design, Development, Implementation, and Evaluation stages. The method of data collection in this study used a questionnaire method and a rating scale instrument. The data analysis technique used qualitative descriptive statistical data analysis and quantitative descriptive statistics. The results of this study are the results that the percentage obtained in terms of the material as a whole is $96.66 \%$. The results of the percentage of learning material experts are in the range of 90-100 with very good qualifications and do not need to be revised. The results of the calculation of the percentage of the validity test in terms of learning media as a whole are 88.88\%. The results of the percentage of learning media experts are in the range of 90-100 with very good qualifications and do not need to be revised. Meanwhile, the practitioner test stated that the learning module was in very good qualification with an overall percentage of $94.5 \%$. So, Civics learning modules containing tolerance character values are feasible to be used in learning. The implication of this research is that the Civics learning module containing the value of the character of tolerance can help students in the learning process.

\section{PENDAHULUAN}

Pembelajaran merupakan suatu kegiatan interaksi antara guru dengan siswa dalam proses pembelajaran (Laili et al., 2019; Sulistyaningrum et al., 2018). Pentingnya pembelajaran merupakan upaya pendampingan oleh guru untuk menyampaikan informasi terkait ilmu kepada peserta didik (Tegeh \& Kirna, 2013; Winarno et al., 2020). Pembelajaran memiliki beberapa komponen antaralain siswa yang mana proses pembelajaran pada dasarnya diadakan untuk pembelajaran siswa dalam mencapai tujuan yang ditentukan, pembelajaran juga memiliki tujuan yang merupakan arah yang harus jadi rujukan dalam proses pembelajaran, dengan adanya tujuan, maka guru memiliki pedoman dan sasaraan yang akan 
dicapai dalam kegiatan mengajar. Apabila tujuan pembelajaran sudah jelas dan tegas, maka langkah dan kegiatan pembelajaran akan lebih terarah (Pane \& Dasopang, 2017), kemudian kondisi dalam berbagai pengalaman belajar yang yang dirancang agar siswa mampu mencapai tujuan yang telah dirumuskan, lalu terdapat sumber belajar, segala sesuatu yang berkaitan memungkinkan siswa mampu mendapatkan pengalaman belajar yang meliputi tempat belajar, bahan dan alat, serta tutorial belajar dan terakhir adalah hasil belajar dimana pencapaian dalam memperoleh kemampuan disesuaikan dengan tujuan yang ingin dicapai (Heriyani et al., 2021). Oleh karena itu, pembelajaran bermakna sebagai suatu proses dalam membantu siswa dalam memahami materi yang dilakukan oleh guru. Proses pembelajaran dapat dikatakan baik yaitu proses pembelajaran yang aktif dan efektif (Seruni et al., 2019; Susilowati et al., 2018).

Pembelajaran yang aktif dan efektif seharusnya terjadi pada semua mata pelajaran termasuk mata pelajaran Pendidikan Kewarganegaraan (PPKn) di sekolah dasar. Menciptakan pembelajaran PKn yang mampu mengembangkan kemampuan dalam pembelajaran PPKn tidaklah mudah. Pembelajaran PPKn diupayakan agar mampu mempersiapkan siswa memiliki kepribadian yang baik. PPKn membantu siswa dalam memiliki sikap menghormati dan tenggang rasa terhadap sesama, karena pada pembelajaran PPKn diberikan nilai-nilai bagaimana bertingkah laku yang baik yang sesuai dengan Pancasila serta nilai karakter yang baik (Rizki, 2018). Pendidikan karakter merupakan pendidikan yang mengembangkan nilai budaya dan karakter pada siswa, sehingga siswa dapat menerapkan nilai karakter tersebut dalam kehidupan sehari-hari. Pada hakikatnya pembelajaran PPKn mengajarkan hidup di dalam kebhinekaan, salah satu nilai karakter yang tidak bisa berlangsung di dalam kegiatan pembelajaran yang mengajarkan kebhinekaan adalah nilai torelasi (Claudia et al., 2020; Muhamad Nova, 2017; Sirnayatin, 2017). Toleransi adalah suatu sikap atau sifat dari seseorang untuk membiarkan kebebasan kepada orang lain serta memberikan kebenaran atas perbedaan tersebut sebagai pengakuan hak-hak asasi manusia (Afifah, 2019; Christopher et al., 2019; Rahmawati \& Harmanto, 2020). Nilai torelansi tidak hanya berlangsung dalam kegiatan pembelajaran PPKn saja, namun harus diterampkan pada kehidupan sehari-hari. Selain penerapan nilai toleransi, implementasi pembelajaran PPKn di sekolah dasar yang terintegrasi dalam pembelajaran tematik (Hasibuan \& Indonesia, 2021; Witasari \& Wiyani, 2020). Pembelajaran PPKn yang aktif dan efektif dapat dikatakan baik apabila dalampembelajaran juga didukung dengan bahan ajar yang memumpuni. Menciptakan proses pembelajaran efektif guru perlu menggunakan bahan ajar seperti modul, media, dan metode pembelajaran. Perangkat pembelajaran yang baik merupakan perangkat pembelajaran yang praktis dan dapat membantu siswa dalam memahami materi (Apriyanti et al., 2018; Asdarina \& husnul khatimah, 2021). Salah satu perangkat pembelajaran yaitu bahan ajar berupa modul. Modul yang baik merupakan modul yang dapat digunakan siswa dalam mengembangkan kemampuan dan keterampilan belajar secara mandiri (Solihudin JH, 2018; Suastika \& Amaylyla, 2019).

Namun, kenyataannya masih terjadi permasalahan yang berkaitan dengan buku pegangan siswa diantaranya banyak kompetensi dasar kurikulum 2013 yang tidak terdapat pada buku, silabus, maupun tidak sesuai dengan Peraturan Meteri Nomor 57 Tahun 2014 (Novika Auliyana et al., 2018; Subhan et al., 2017). Buku pegangan siswa juga tidak selalu sesuai dengan situasi, kondisi, dan kebutuhan siswa (Febriani \& Widiastuti, 2017; Firman et al., 2018; Mukaromah, 2018). Dalam beberapa kegiatan pembelajaran integrasi mata pelajaran yang membentuk tema/subtema belum terlihat (Onde et al., 2020; Sasmito \& Mustadi, 2015; Setiawan, 2020). Materi pembelajaran masih kurang relevan dengan kompetensi yang dibutuhkan. Dangkalnya materi ajar juga berdampak pada sempitnya pengetahuan siswa dalam penerapannya (Gerhardt-Szép et al., 2017b; Solihudin JH, 2018). Berdasarkan hasil wawancara kepada guru kelas di sejumlah SD desa Bunutin ditemukan beberapa masalah. Kurangnya buku ajar dan penunjang untuk menyajikan pengajaran PPKn yang efektif terutama pada pelajaran tema 7 SD kelas V. Belum ada pengembangan bahan ajar yang membantu siswa untuk belajar mandiri dan menunjukkan nilai karakter toleransi. Tingkat pemhaman masing-masing siswa berbeda-beda, sehingga siswa yang memiliki kemampuan rendah akan lebih sulit memahami materi yang ada pada buku ajar. Belum terdapat modul pembelajaran PPKn yang memuat nilai katakter torelansi. Kegiatan pembelajaran PPKN pada buku pedoman guru tidak sesuai dengan kondisi di SD Bunutin, dan langkah-langkah kegiatan pembelajaran, alat evaluasi, lembar kerja siswa pada mata pelajaran PPKn belum tersusun secara sistematis. Jika permasalahan tersebut dibiarkan akan memberikan dampak pada kualitas pendidikan.

Solusi yang dapat ditawarkan yaitu dengan menerapkan modul pembelajaran. Modul merupakan sarana pembelajaran yang berisi materi pembelajaran, petunjuk kegiatan pembelajaran, latihan dan cara mengevaluasi yang dirancang secara sistematis dan menarik untuk mencapai kompetensi yang diharapkan dan digunakan secara mandiri (Putra et al., 2017; Ramadhan et al., 2020; Safitri et al., 2021). Modul dapat memotivasi peserta didik, mengetahui kemampuan peserta didik secara individu, dan mengetahui sejauh mana kemampuan setiap peserta didik (Abidin \& Walida, 2017; Komang Redy Winatha et al., 2018). modul yang akan dirancang bermuatan nilai karakter toleransi. Pendidikan nilai karakter 
toleransi akan berhasil dengan baik jika melibatkan baik fisik maupun mental emosionalnya (Nurohmah \& Dewi, 2021; Sadia, 2013). Modul salah satu bahan ajar mempunyai salah satu karakteristik adalah prinsip belajar mandiri (Hamzah \& Mentari, 2017; Tien \& Osman, 2012). Belajar mandiri adalah cara belajar aktif untuk mengembangkan diri masing-masing individu. Modul pembelajaran yang digunakan siswa sebagai sarana pembelajaran perlu diintegrasi dengan metode, model pembelajaran agar dapat meningkatkan hasil belajar.

Temuan penelitian sebelumnya menyatakan bahwa perancangan perangkat pembelajaran yang baik dapat menciptakan suasana belajar yang baik (Hartini, 2017; Prayito, 2011). Modul pembelajaran dapat membantu siswa dalam proses pemberlajaran (Komikesari et al., 2020; Putra et al., 2017; Wibowo, 2018). Modul pembelajaran dapat membantu siswa dalam proses pembelajaran secara mandiri (Komikesari et al., 2020; Neppala et al., 2018). Perbedaan penelitian ini dengan penelitian sebelumnya yaitu modul yang diberikan hanya terfokus pada kemampuan kognitif siswa. Urgensi penelitian ini yaitu belum adanya kajian mengenai modul pembelajaran PPKn bermuatan nilai karakter toleransi yang dapat membantu siswa memahami nilai-nilai karakter dalam kehidupan sehari-hari. Nilai karakter sangat penting untuk ditanamkan pada siswa sekolah dasar, untuk menanamkan nilai karakter dapat dilakukan melalui proses pembelajaran menggunakan modul ataupun media lainnya (Afifah, 2019; Ramdhani et al., 2019). Kelebihan modul yang akan dikembangkan yaitu modul ini berisikan gambar yang sesuai dengan karakteristik siswa sekolah dasar sehingga memudahkan siswa dalam memahami materi pelajaran. Gambar dapat menarik minat siswa untuk mengikuti pembelajaran (Gerhardt-Szép et al., 2017a; Wibowo, 2018). Selain itu modul ini bermuatan nilai karakter toleransi yang dapat meningkatkan kemampuan afektif siswa dalam belajar. Tujuan penelitian ini yaitu untuk mengembangkan modul pembelajaran PPKn bermuatan nilai karakter toleransi pada kelas V sekolah dasar. Diharapkan media ini dapat membantu siswa dalam belajar sehingga dapat meningkatkan hasil belajar siswa dan karakter siswa.

\section{METODE}

Jenis penelitian ini adalah penelitian pengembangan. Model yang dijadikan acuan pada penelitian pengembangan media pembelajaran ini yaitu model ADDIE meliputi tahapan Analyze, Design, Development, Implementation, dan Evaluation. Pemilihan model ini didasari atas pertimbangan bahwa model ini sangat mudah untuk dipahami, memiliki alur yang sistematis, dan begitu jelas. Subjek pada penelitian ini yaitu 2 orang ahli materi muatan pelajaran PPKn, 2 orang ahli media dan desain pembelajaran, 2 orang praktisi oleh guru. Teknik yang digunakan dalam mengumpulkan data pada penelitian ini adalah kuesioner dengan instrument yang digunakan instrument rating scale. Adapun kisikisi instrumen pengumpulan data untuk mengetahui validitas modul pembelajaran yang dikembangkan disajikan pada Tabel 1, 2, dan 3.

Tabel 1. Kisi-kisi Lembar Ahli Media

\begin{tabular}{|c|c|c|c|}
\hline Aspek & Indikator & No Butir & $\begin{array}{c}\text { Jumlah } \\
\text { Butir }\end{array}$ \\
\hline \multirow{5}{*}{$\begin{array}{l}\text { Ukuran } \\
\text { modul } \\
\text { Desain Cover }\end{array}$} & Ukuran modul sesuai dengan standar ISO & 1 & \multirow[t]{2}{*}{2} \\
\hline & Kesesuaian ukuran dengan materi isi modul & 2 & \\
\hline & Gambar mencerminkan isi modul & 3 & \multirow[t]{3}{*}{3} \\
\hline & $\begin{array}{l}\text { Kesesuain jenis huruf, warna spasi dan ukuran font, dan } \\
\text { posisi judul modul }\end{array}$ & 4 & \\
\hline & Ketepatan pengaturan objek teks maupun gambar & 5 & \\
\hline Desain Pesan & Kesesuain jenis dan ukuran huruf & 6 & 2 \\
\hline \multirow[t]{5}{*}{ Teks } & Kesesuaian warna dan spasi & 7 & \\
\hline & Ketepatan susunan klimat dalam suatu paragraph & 8 & \multirow[t]{4}{*}{4} \\
\hline & Ketepatan penggunaan simbol dan tanda baca & 9 & \\
\hline & Kejelasan petunjuk penggunaan modul & 10 & \\
\hline & Kesesuain warna background dengan teks & 11 & \\
\hline \multirow{5}{*}{$\begin{array}{l}\text { Desain Pesan } \\
\text { gambar }\end{array}$} & Kesesuaian gambar dengan pesan teks (materi) & 12 & \multirow[t]{5}{*}{5} \\
\hline & $\begin{array}{l}\text { Kesesuain keterangan gambar dengan gambar yang } \\
\text { diterangkan }\end{array}$ & 13 & \\
\hline & Ketepatan posisi gambar dengan sajian teks & 14 & \\
\hline & Kualitas warna gambar poposional & 15 & \\
\hline & Tata letak gambar proposional & 16 & \\
\hline Sampul & Kesesuaian gambar latar & 17 & 2 \\
\hline belakang & Kelengkapan komponen lain (identitas penulis) & 18 & \\
\hline
\end{tabular}


Tabel 2. Kisi-kisi Ahli Materi

\begin{tabular}{|c|c|c|c|}
\hline Aspek & Indikator & Butir & Jumlah Butir \\
\hline \multirow[t]{5}{*}{ Isi } & Kesesuain materi dengan KD dan Indikator & 1 & \multirow[t]{5}{*}{ (2) } \\
\hline & $\begin{array}{l}\text { Kelengkapan materi pembelajaran dengan } \\
\text { urutan dan susunan yang sistematis }\end{array}$ & 2 & \\
\hline & Materi mudah dimengerti & 3 & \\
\hline & Materi mampu memotifasi belajar & 4 & \\
\hline & Materi membuat nilai toleransi & 5 & \\
\hline \multirow[t]{3}{*}{ Bahasa } & Bahasa yang digunakan mudah dipahami & 6 & \multirow[t]{3}{*}{4} \\
\hline & Kebakuan bahasa yang digunakan. & 7 & \\
\hline & Keefektifan kalimat yang digunakan. & 8 & \\
\hline \multirow[t]{3}{*}{ Aspek Evaluasi } & $\begin{array}{l}\text { Kesesuaian jenis latihan soal/tes dengan } \\
\text { materi }\end{array}$ & 9 & \multirow{3}{*}{3} \\
\hline & $\begin{array}{l}\text { Kesesuaian jumlah soal/tes dengan tujuan } \\
\text { pembelajaran }\end{array}$ & 10 & \\
\hline & Kejelasan petunjuk pengerjaan soal/tes & 11 & \\
\hline \multirow[t]{2}{*}{ Aspek belajar mandiri } & Dapat menarik minat siswa dalam belajar & 12 & \multirow[b]{2}{*}{2} \\
\hline & $\begin{array}{l}\text { Dapat membantu siswa dalam belajar } \\
\text { mandiri }\end{array}$ & 13 & \\
\hline
\end{tabular}

Tabel 3. Kisi-kisi Praktisi (Guru)

\begin{tabular}{clcc}
\hline Aspek & \multicolumn{1}{c}{ Indikator } & No Butir & Jumlah Butir \\
\hline \multirow{5}{*}{ Bahasa } & $\begin{array}{l}\text { Kesesuaian bahasa dengan kaidah penulisan yang } \\
\text { baik dan benar }\end{array}$ & 1 & 3 \\
& $\begin{array}{l}\text { Susunan kalimat dapat dipahami oleh guru } \\
\text { Susunan kalimat mendukung pencarian data yang } \\
\text { berkaitan dengan tema penelitian } \\
\text { Pertanyaan yang diajukan sesuai dengan konteks } \\
\text { nyata kehidupan guru }\end{array}$ & 3 \\
$\begin{array}{l}\text { Pertanaan yang diajukan sesuai dengan tingkat } \\
\text { pemahaman guru dertanyaan }\end{array}$ & 5 \\
$\begin{array}{l}\text { Pertanyaan yang diajukan untuk mengetahui } \\
\text { pembelajaran yang diperlukan guru }\end{array}$ & 6 \\
\hline
\end{tabular}

Suatu instrumen dapat dikatakan baik apabila memenuhi syarat validitas isi. Instrumen yang disusun agar dapat dikatakan valid, maka dapat dilakukan uji validitas isi oleh beberapa ahli (judges). Uji validitas instrument ini dilakukan dengan menggunakan rumus Gregory. Berdasarkan kriteria validitas isi, koevisien validitas isi ketiga instrumen berada pada kriteria validitas isi sangat tinggi. Metode dan teknik analisis data yang digunakan pada penelitian pengembangan ini yaitu menggunakan teknik analisis statistik deskriptif kuantitatif. Analisis statistik deskriptif kuantitatif digunakan untuk mengolah data yang berupa angka-angka yang diperoleh dari pemberian lembar penilaian intrumen media pembelajaran yang dikembangkan kepada ahli media pembelajaran, ahli materi pembelajaran, ahli muatan PPKn dan guru. Skor yang didapatkan dari masing-masing indikator penilaian dapat dihitung dalam bentuk deskriptif persentase untuk mengetahui validitas media pembelajaran yang dikembangkan. Untuk dapat memberikan makna dan pengambilan keputusan digunakan ketepatan yang ditunjukkan pada Tabel 4.

Table 4. Penilaian Skala Lima

\begin{tabular}{ll}
\hline Rentangan Skor & Klasifikasi Predikat \\
\hline $4,01<X \leq 5,01$ & Sangat Baik \\
$3,34<X \leq 4,01$ & Baik \\
$2,66<X \leq 3,34$ & Cukup \\
$1,99<X \leq 2,66$ & Tidak Baik \\
$0,99<X \leq 1,99$ & Sangat Tidak Baik \\
\hline
\end{tabular}




\section{HASIL DAN PEMBAHASAN}

Hasil

Proses pengembangan modul pembelajaran PPKn bermuatan nilai karakter toleransi telah dilakukan dengan model pengembangan yang digunakan yaitu model pengembangan ADDIE. Desain pengembangan modul pembelajaran PPKn bermuatan nilai karakter toleransi dimulai pada tahap analisis, desain dan pengembangan. Adapun tahapan Implementasi dan Evaluasi tidak dilakukan pada penelitian pengembangan ini. Pada tahapan analisis (analyze), analisis kebutuhan dilakukan di SD Negeri Bunutin tepatnya di kelas V bersama guru kelas dengan melaksanakan wawancara menyatakan pada buku tema 7 khususnya pada muatan nilai karakter toleransi energi kurang lengkap, masih sangat terbatas, sempit sedangkan cakupan materi yang ada sangat luas dan perlu ditambahkan kembali materi dari sumber lain agar menunjang proses pembelajaran ditengah pendemi ini. Pembelajaran yang dilakukan ditengah pandemic covid 19 ini penggunaan dan pengembangan media belum dilakukan dan belum diterapkan, guru masih cenderung menggunakan metode penugasan dan masih berpedoman pada buku siswa tanpa penggunaan media apapun. Hal ini mengakibatkan siswa kurang antusias dan kurang bersemangat melakukan pembelajaran daring. Selain itu, minimnya sarana dan prasarana baik berupa media gambar, media pembelajaran baik dari video pembelajaran maupun dari buku yang dipakai oleh guru ditengah pandemic covid 19 ini untuk menunjang proses pembelajaran daring. Minimnya media yang digunakan menjadi acuan untuk perlunya dikembangkan modul pembelajaran PPKn muatan nilai karakter toleransi di SD Negeri Bunutin. Modul pembelajaran PPKn muatan nilai karakter toleransi yang dikembangkan berpedoman pada aspek praktis dan aspek efektif dalam penggunaannya. Analisis kurikulum dilakukan dengan menganalisis dan menentukan terlebih dahulu kompetensi inti, kompetensi dasar, indikator pencapaian kompetensi, tujuan pembelajaran, dan materi yang terdapat pada buku guru dan buku siswa sebagai dasar dalam penyusunan media pembelajaran yang akan dikembangkan. Pembuatan media pembelajaran ini berpedoman pada buku materi pada muatan nilai karakter toleransi kelas $\mathrm{V}$ sekolah dasar. Pada hasil analisis tersebut akan dikembangkan dalam bentuk modul pembelajaran PPKn yang sesuai dengan kurikulum 2013. Kompetensi dasar dan indikator pencapaian kompetensi disajikan pada Tabel 5.

Tabel 5. Kompetensi Dasar dan Indikator Pencapaian Kompetensi

\begin{tabular}{|c|c|}
\hline Kompetensi Dasar (KD) & Indikator Pencapaian Kompetensi \\
\hline $\begin{array}{l}3.3 \text { Menelaah keberagaman social } \\
\text { budaya masyarakat }\end{array}$ & $\begin{array}{l}\text { 4.3.1 Menyelenggarakan kegiatan yang mendukung } \\
\text { keberagaman social budaya masyarakat }\end{array}$ \\
\hline
\end{tabular}

Tahap kedua yang dilakukan yaitu desain. Tahap perancangan, modul pembelajaran PPKn muatan nilai karakter toleransi dilakukan dengan mengacu pada tahap analisis yang sudah dilakukan sebelumnya. Pada tahapan ini dimulai dari melakukan pemindahan informasi yang didapatkan pada tahap analisis ke dalam bentuk dokumen yang akan menjadi dasar dan tujuan modul pembelajaran PPKn muatan nilai karakter toleransi. Tujuannya untuk memberikan gambaran dan alur modul pembelajaran yang akan dikembangkan. Modul secara lengkap terlampir pada lampiran. Modul pembelajaran yang dikembangkan berisi tahapan alur yaitu sampul, judul dari video pembelajaran, nama pembuat modul, kompetensi dasar dan indikator pencapaian kompetensi modul pembelajaran, alur materi modul pembelajaran yang digunakan. Tahap ketiga pengembangan (Development), tahap pengembangan dilakukan dengan merancang dan membuat modul pembelajaran PPKn muatan nilai karakter toleransi. Selanjutnya, dilakukan penelitian terhadap produk tersebut oleh para ahli dan praktisi untuk mengetahui validitas modul pembelajaran yang dikembangkan serta memperoleh saran dan komentar, sehingga dapat dilakukan perbaikan terhadap media agar menjadi media yang layak untuk digunakan dalam proses pembelajaran. Berdasarkan hasil perhitungan rata-rata skor uji validitas diperoleh hasil bahwa persentase yang diperoleh dari segi materi secara keseluruhan yaitu 96,66\%. Hasil persentase dari ahli materi pembelajaran berada pada rentangan 90-100 dengan kualifikasi sangat baik dan tidak perlu direvisi. Hasil perhitungan persentase uji validitas dari segi media pembelajaran secara keseluruhan yaitu 88,88\%. Hasil persentase dari ahli media pembelajaran berada pada rentangan 90-100 dengan kualifikasi sangat baik dan tidak perlu direvisi. Sementara itu, dari uji praktisi menyatakan bahwa modul pembelajaran ada pada kualifikasi sangat baik dengan persentase keseluruhan yaitu 94,5\% Berdasarkan hasil tersebut modul pembelajaran PPKn bermuatan nilai karakter toleransi dinyatakan valid dengan kualifikasi sangat baik. Gambar modul pembelajaran PPKn yang sudah dirancang, terdiri dari cover, judul video pembelajaran, nama perancang modul pembelajaran, kompetensi dasar dan indikator pencapaian kompetensi, isi materi pembelajaran, dan penutup. Cover modul pembelajaran PPKn muatan nilai 
karakter toleransi memuat identitas instansi perancang video. Modul pembelajaran dilengkapi kata pengantar, petunjuk pengguanaan modul, dan daftar isi. Modul pembelajaran yang dihasilkan di Tunjukkan pada Gambar 2.

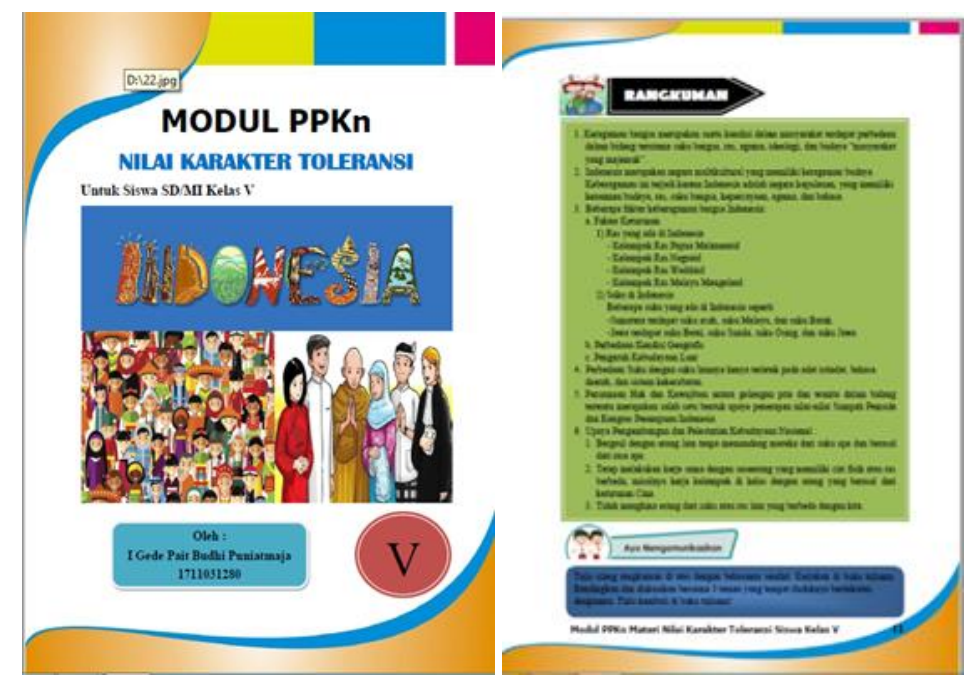

\section{Gambar 2. Rancangan Modul Pembelajaran PPKn bermuatan Nilai Karakter}

Tahap keempat yaitu implementasi (Implementation), tahap implementasi dilakukan dengan menerapkan media pembelajaran yang sudah dirancang dan dikembangkan dalam suatu proses pembelajaran. Pada tahapan ini membuat catatan tentang kekurangan dan kendala yang ditemui pada media pembelajaran yang dikembangkan. Pada penelitian pengembangan ini tahap implementasi tidak dilakukan karena keterbatasan waktu. Tahap evalusi ini merupakan tahapan yang terakhir untuk mengavaluasi produk yang telah dikembangkan. Pada tahapan evalusi ini juga tidak dilakukan karena keterbatasan waktu. Adapun saran dan masukan yang diberikan oleh ahli media pembelajaran demi kesempurnaan media ini yaitu; (1) pada cover tambahkan untuk kelas V SD, (2) tambahkan petunjuk penggunaan modul, (3) beberapa teks dan latar yang tidak kontras (sama-sama gelap), 4) tambahkan nama dosen pembimbing di akhir modul. kabur. Setelah menganalisis saran yang diberikan oleh ahli desain pembelajaran, selanjutnya adalah merevisi produk sesui dengan saran yang telah diberikan.

Berdasarkan hasil analisis data yang telah dilakukan maka modul pembelajaran PPKn bermuatan nilai karakter toleransi mendapatkan kualifikasi sangat baik, sehingga layak untuk diterapkan dalam proses pembelajaran. Modul pembelajaran PPKn bermuatan nilai karakter toleransi ini wajib dikembangkan karena modul pembelajaran PPKn bermuatan nilai karakter toleransi ini dapat memfasilitasi siswa belajar secara mandiri dan menyenangkan sehingga siswa dapat memahami materi pembelajaran dengan baik. Selain itu, adanya modul pembelajaran ini juga dapat membantu guru dalam penyampaian materi pembelajaran kepada siswa khususnya pada nilai karakter toleransi. Hal ini sesuai dengan analisis kebutuhan menunjukkan bahwa perlu adanya media pembelajaran yang dapat digunakan oleh guru dan siswa dalam kegiatan pembelajaran dimasa pandemi covid-19. Hasil analisis kurikulum menunjukkan dengan menganalisis KI, KD, indikator pencapaian kompetensi, tujuan pembelajaran, dan materi pembelajaran yang terdapat pada buku sebagai dasar dalam menyususn media pembelajaran yang dikembangkan. Modul pembelajaran PPKn bermuatan nilai karakter toleransi yang dikembangkan berfokus pada siswa kelas V SD yang sesuai dengan kurikulum 2013. Oleh karena itu, modul pembelajaran PPKn bermuatan nilai karakter toleransi dikembangkan agar bisa memudahkan siswa dalam memahami materi pembelajaran selama pandemi Covid-19.

\section{Pembahasan}

Hasil penelitian menunjukkan bahwa modul pembelajaran PPKn bermuatan nilai karakter toleransi ini mendapatkan kualifikasi sangat baik dan layak diterapkan disebabkan oleh beberapa faktor yaitu sebagai berikut. Pertama, pengembangan modul pembelajaran PPKn bermuatan nilai karakter toleransi sudah layak digunakan karena berdasarkan penilaian dari hasil uji media pembelajaran berada pada kualifikasi sangat baik pada aspek materi. Materi yang disajikan dalam modul pembelajaran harus sesuai dengan tujuan pembelajaran dan ketersediaan contoh untuk mendukung kejelasan materi. Pembelajaran dengan menggunakan modul dapat membuka kesempatan bagi siswa untuk belajar 
menurut kecepatan masing-masing, siswa tidak akan mencapai hasil yang sama dalam waktu yang sama dan tidak mempelajari sesuatu yang sama pada waktu yang sama (Jannah et al., 2021; Laili et al., 2019). Pengajaran modul juga memberi kesempatan bagi siswa untuk belajar menurut caranya masing-masing. Modul nantinya mampu meningkatkan hasil belajar peserta didik dan efektif dalam mencapai kompetensi yang diharapkan sesuai dengan tingkat kompleksitasnya. Modul memiliki karakteristik dan tujuan tertentu dapat membantu siswa dalam proses pembelajaran (Amini \& Oktarisma, 2021; Gerhardt-Szép et al., 2017a; Lestari, 2021; Safitri et al., 2021). Karakteristik modul, bentuk unit pengajaran terkecil dan lengkap, berisi rangkaian kegiatan belajar yang dirancang secara sistematis, berisi tujuan yang merumuskan secara jelas dan khusus, memungkinkan siswa belajar mandiri dan merupakan realisasi perbedaan individu serta perwujudan pengajaran individual.

Kedua, pada aspek desain, ukuran modul, desain cover, desain pesan teks, desain pesan gambar dan sampul belakang disesuaikan dengan karakteristik siswa. Modul ini memiliki kejelasan gambar, kesesuaian pemilihan warna, dan penggunaan contoh konkret sangat baik sehingga memudahkan siswa dalam memahami materi yang disajikan. Dengan menggunakan gambar, siswa akan lebih tertarik menggunakan modul pembelajaran(Groth et al., 2018; Kulagin et al., 2021; Wibowo \& Pratiwi, 2018). Selain itu, dalam media dijelaskan melalui contoh gambar yang konkret memudahkan siswa dalam memahami materi (Gunawan et al., 2017; Muskania et al., 2019; Taqiya et al., 2019). Media pembelajaran dapat membantu siswa dalam jika mengalami kesulitan dalam memahami materi. Tujuan pengajaran dengan menggunakan modul yaitu para siswa dapat mengikuti program pengajaran sesuai dengan kecepatan dan kemampuan sendiri, lebih banyak belajar mandiri, dapat mengetahui hasil belajar sendiri, dan menentukan penguasaan bahan pelajaran secara optimal.

Ketiga, pengembangan modul pembelajaran PPKn bermuatan nilai karakter toleransi sudah layak digunakan dari segi aspek bahasa. Bahasa yang digunakan sederhana dan mudah dipahami, sehingga siswa dapat belajar dengan mandiri. Salah satu manfaat penggunaan media pembelajaran dalam pembelajaran adalah memperjelas penyajian pesan sehingga proses pembelajaran lancar dan hasil belajar meningkat. modul menuntut siswa berinteraksi secara aktif dengan materi pembelajaran, tidak hanya pasif membaca materi saja (Desira et al., 2020; Maghfiroh \& Hardini, 2021; Torlakson, 2014). Selain itu siswa diminta melakukan kegiatan pembelajaran dan mendapatkan tanggapan atas apa yang mereka lakukan. Artinya, modul mengharuskan siswa untuk secara aktif berinteraksi dengan materi belajar, tidak hanya pasif membaca materi saja. Dengan menggunakan modul berarti siswa belajar sendiri sesuai dengan kemampuannya. Selain siswa dapat menilai kemajuannya sendiri, sebab setiap langkah kegiatan belajar dikontrol sendiri (Nakayama, M \& Yamamoto., 2006; Nilawati et al., 2020; Tien \& Osman, 2012). Dengan demikian hasil belajarpun dapat selalu diketahui. Apabila hasil belajar masing-masing telah diketahui, siswa akan belajar dengan lebih aktif. Modul adalah salah satu bentuk bahan ajar bermuatan cetak yang dirancang untuk belajar secara mandiri oleh peserta pembelajaran karena itu modul dilengkapi dengan petunjuk untuk belajar sendiri. Dalam hal ini peserta didik dapat melakukan kegiatan belajar sendiri tanpa kehadiran pengajar secara langsung (Abidin \& Walida, 2017; Bock et al., 2018; Hamzah \& Mentari, 2017).

Temuan ini diperkuat dengan penelitian sebelumnya yang menyatakan bahwa modul pembelajaran efektif digunakan pada proses pembelajaran (Apriyanti et al., 2018; Susilowati et al., 2018; Suwasono, 2013). Temuan lain juga menyatakan bahwa modul pembelajaran dapat digunakan dalam mengembangkan nilai-nilai karakter siswa (Amania et al., 2021; Pitaloka et al., 2021; Solihudin JH, 2018). Pengajaran modul juga memberi kesempatan bagi siswa untuk belajar menurut caranya masing-masing. Modul nantinya mampu meningkatkan hasil belajar peserta didik dan efektif dalam mencapai kompetensi yang diharapkan sesuai dengan tingkat kompleksitasnya (Mukaromah, 2018; Ramadhan et al., 2020). Modul pembelajaran yang dapat membantu siswa selama proses pembelajaran secara terarah (GerhardtSzép et al., 2017b; Komikesari et al., 2020; Kulagina et al., 2021). Temuan lain juga menyatakan dengan menggunakan modul, guru dapat mengorganisasi fasilitas, perlengkapan, alat bantu pengajaran, waktu dan isi dalam rangka untuk mencapai tujuan belajar seefektif mungkin serta menghubungkan tujuan dan prosedur kepada tujuan keseluruhan dari mata pelajaran yang diajarkan (Bock et al., 2018; Firman et al., 2018; Ramli \& Tajudin, 2021).

Berdasarkan pembahasan dapat dipahami bahwa modul pembelajaran PPKn bermuatan nilai karakter toleransi mendapatkan kualifikasi sangat baik, sehingga layak untuk diterapkan dalam proses pembelajaran kelas V di SD, termasuk di SD Desa Bunutin. Temuan yang ada menunjukkan bahwa pengembangan modul memiliki kesesuaian dengan karakteristik siswa, pencapaian KD dan indicator serta kebutuhan. Hal ini dapat dilihat dari hasil validasi dari para ahli/pakar. Namun pengembangan modul ini memiliki keterbatasan yaitu modul pembelajaran PPKn bermuatan nilai karakter ini hanya mengembangkan pada satu KD dan indikator. Selain itu, modul ini hanya dikembangkan sampai uji praktisi. Maka diharapkan penelitian selanjutnya dapat mengembangkan penelitian ini pada tahap 
implementasi melalui tahap eksperimen. Adanya modul ini dapat dimanfaatkan dalam proses pembelajaran PPKn khususnya dalam mengembangakan nilai karakter toleransi. Modul ini dapat memfasilitasi siswa dalam mengembangkan nilai karakter toleransi agar lebih mudah dipahami siswa sehingga dapat diterapkan dalam kehidupan sehari-hari. Implikasi penelitian ini diharapkan dapat memberikan dampak bagi siswa dalam proses pembelajaran, sehingga dapat meningkatkan hasil belajar PPKn.

\section{SIMPULAN}

Modul pembelajaran PPKn bermuatan nilai karakter toleransi layak diterapkan dalam proses pembelajaran karena agar dapat membantu siswa dalam memahami materi dan dapat diterapkan oleh siswa dalah kehidupan sehari-hari. Selain itu dapat membantu guru dalam menyampaikan materi. Diharapkan dengan adanya modul ini dapat memfasilitasi siswa serta meningkatkan hasil belajar siswa sehingga kegiatan pembelajaran dapat terlaksana dengan efektif dan efisien serta tujuan pembelajaran dapat tercapai.

\section{DAFTAR PUSTAKA}

Abidin, Z., \& Walida, S. El. (2017). Pengembangan E-Modul Interaktif Berbasis Case (Creative , Active , Systematic, Effective) Sebagai Alternatif, Media Pembelajaran Geometri Transformasi Untuk Mendukung Kemandirian Belajar Dan Kompetensi Mahasiswa. Seminar Nasional Matematika Dan Aplikasinya, 197-202. conference.unisma.ac.id/index.php/icotte/ICOTTE2018/paper/view/194

Afifah, N. (2019). Efektivitas Media Ajar untuk Siswa Kelas Rendah Berbasis Nilai Karakter Toleransi terhadap Sesama dengan Berbantu Aplikasi Sparkol Videoscribe. Modeling: Jurnal Program Studi PGMI, 6(2). https://doi.org/https://doi.org/10.36835/modeling.v6i2.512.

Amania, M., Nugrahanta, G. A., \& Irine Kurniastuti. (2021). Pengembangan Modul Permainan Tradisional sebagai Upaya Mengembangkan Karakter Adil pada Anak Usia 9-12 Tahun. Elementary School, 8(2), 237-251. https://doi.org/10.31316/esjurnal.v8i2.1230.

Amini, Ri., \& Oktarisma, S. (2021). Pengembangan Modul Pembelajaran IPA Berbasis Picture and Picture di Sekolah Dasar. Jurnal Basicedu, 5(2), 835-841. https://doi.org/10.31004/basicedu.v5i2.769.

Apriyanti, R., Lufri, \& Putri, D. H. (2018). Pengembangan Modul Bernuansa Spiritual dalam Bentuk Komik Strip pada Materi Sistem Reproduksi Manusia untuk Siswa Kelas XI SMA/MA. Bioeducation Journal, 2(2). https://doi.org/10.24036/bioedu.v2i2.12.

Asdarina, 0., \& husnul khatimah. (2021). Pengembangan Modul Pembelajaran Matriks Berbantuan Aplikasi Geogebra. Jurnal Program Studi Pendidikan Matematika, 10(2), 860-871. https://doi.org/10.24127/ajpm.v10i2.3515.

Bock, A., Modabber, A., Kniha, K., Lemos, M., Rafai, N., \& Hölzle, F. (2018). Blended learning modules for lectures on oral and maxillofacial surgery. British Journal of Oral and Maxillofacial Surgery, 56(10), 956-961. https://doi.org/10.1016/j.bjoms.2018.10.281.

Christopher, A. E., Waluyanto, H. D., \& Wahyudi, A. T. (2019). Perancangan Board Game Pembelajaran Toleransi Terhadap Perbedaan Pada Pelajaran Ppkn. Jurnal DKV Adiwarna, 2(15), 1-9. https://doi.org/http://publication.petra.ac.id/index.php/dkv/article/view/9733.

Claudia, C., Prabawati, H., Malihah, M., Novrezi, M., Sahara, S., \& Safitri, D. (2020). Pelatihan Pendidikan Karakter pada Anak Pekerja di Yayaysan Swara Peduli Indonesia Jakarta. Jurnal Penelitian Dan Pengabdian Kepada Masyarakat, 8(1). https://doi.org/10.29313/ethos.v8i1.4909.

Desira, Khaldun, I., Maulana, I., Habibati, \& Ismyani, A. (2020). The effectiveness of an interactive module in improving students ' conceptual understanding of acid-base titration The effectiveness of an interactive module in improving students ' conceptual understanding of acid-base titration. Journal of Physics: Conference Series. https://doi.org/10.1088/1742-6596/1460/1/012092.

Febriani, F. D., \& Widiastuti, A. (2017). Pengembangan Modul Ilmu Pengetahuan Sosial Sebagai Sumber Belajar dengan Materi Kehidupan Pada Masa Praaksara di Indonesia Untuk Siswa SMP Kelas VII. 104-113. https://ejournal.unikama.ac.id/index.php/JPPI/article/view/1896

Firman, Baedhowi, \& Murtini, W. (2018). The Effectiveness of The Scientific Approach to Improve Student Learning Outcomes. International Journal of Active Learning. https://doi.org/https://doi.org/10.15294/ijal.v3i2.13003.

Gerhardt-Szép, S., Dreher, S., Rüttermann, S., \& Weberschock, T. (2017a). Konzeption und Implementierung eines neuartigen E-Learning-Moduls mit EbM-Lerninhalten im Fach Zahnerhaltungskunde. Zeitschrift Fur Evidenz, Fortbildung Und Qualitat Im Gesundheitswesen, 
127-128, 72-78. https://doi.org/10.1016/j.zefq.2017.09.001.

Gerhardt-Szép, S., Dreher, S., Rüttermann, S., \& Weberschock, T. (2017b). Konzeption und Implementierung eines neuartigen E-Learning-Moduls mit EbM-Lerninhalten im Fach ZahnerhaltungskundeConception and implementation of a novel E-learning module with EbM learning contents in operative dentistry. Zeitschrift Für Evidenz, Fortbildung Und Qualität Im Gesundheitswesen, 127-128, 72-78. https://doi.org/10.1016/j.zefq.2017.09.001.

Groth, M., Barthe, K. G., Riemer, M., Ernst, M., Herrmann, J., Fiehler, J., \& Buhk, J. H. (2018). Critical Analysis of an e-Learning and Interactive Teaching Module with Respect to the Interpretation of Emergency Computed Tomography of the Brain. RoFo Fortschritte Auf Dem Gebiet Der Rontgenstrahlen Und Der Bildgebenden Verfahren, 190(4), 334-340. https://doi.org/10.1055/s0043-124191.

Gunawan, G., Sahidu, H., Harjono, A., \& Suranti, N. M. Y. (2017). The effect of project based learning with virtual media assistance on student's creativity in physics. Jurnal Cakrawala Pendidikan, 1(2). https://doi.org/https://doi.org/10.21831/cp.v36i2.13514.

Hamzah, I., \& Mentari, S. (2017). Development of Accounting E-Module to Support the Scientific Approach of Students Grade X Vocational High School. Journal of Accounting and Business Education, 1(1), 78-88. https://doi.org/10.26675/jabe.v1i1.9751.

Hartini, A. (2017). Pengembangan Perangkat Pembelajaran Model Project Based Learning Untuk Meningkat Kemampuan Berpikir Kritis Siswa Sekolah Dasar. Jurnal Pendidikan Dan Pembelajaran Di Sekolah Dasar, 1(2). https://doi.org/http://dx.doi.org/10.30651/else.v1i2a.1038.

Hasibuan, H. A., \& Indonesia, U. P. (2021). Pendidikan Kewarganegaraan: Internalisasi Nilai Toleransi Untuk Mencegah Tindakan Diskriminatif. Jurnal Pendidikan Kewarganegaran, 9(2), 440-453. https: //doi.org/10.23887/jpku.v9i2.34146.

Heriyani, D., Triana, D. D., \& Suwandi, T. (2021). Jauh Pada Pembelajaran Tari Betawi ( Persepsi Bagi Mahasiswa Tari Unj ). Jurnal Pendidikan Tari UNJ, 2(01), 90-100. http://journal.unj.ac.id/unj/index.php/jpt/article/view/19877.

Jannah et al. (2021). Efektivitas Penggunaan E-Modul Terhadap Hasil Belajar Kognitif Pada Materi Sistem Pencernaan Manusia di Madrasah Tsanawiyah. Jurnal Basicedu, 5(2), 1060-1066. https://doi.org/10.31004/basicedu.v5i3.952.

Komang Redy Winatha, N., Suharsono, \& Agustin, K. (2018). Pengembangan E-Modul Interaktif Berbasis Proyek Matematika. Jurnal Pendidikan Teknologi Dan Kejuruan, 4(2), 188-199. https://ejournal.undiksha.ac.id/index.php/JPTK/article/viewFile/14021/9438.

Komikesari, H., Mutoharoh, M., Dewi, P. S., Utami, G. N., Anggraini, W., \& Himmah, E. F. (2020). Development of e-module using flip pdf professional on temperature and heat material IOP Publishing. Journal of Physics, 1572(1), 012017. http://dx.doi.org/10.1088/17426596/1572/1/012017.

Koyan, I. W. (2012). Statistik Pendidikan Teknik Analisis Data Kuantitatif. Undiksha Press.

Kulagin, K., Leksashov, A., Bolsunovskaya, M., \& Shirokova, S. (2021). Development of a Human Flow Generation Module for Testing Machine Learning Algorithms. Transportation Research Procedia, 54, 783-792. https://doi.org/10.1016/j.trpro.2021.02.134.

Kulagina, K., Leksashova, A., Bolsunovskayaa, M., \& Shirokovaa, S. (2021). Development of a Human Flow Generation Module for Testing Machine Learning Algorithms. Transportation Research Procedia, 54, 783-792. https://doi.org/10.1016/j.trpro.2021.02.134.

Laili, I., Ganefri, \& Usmeldi. (2019). Efektivitas Pengembangan E-Modul Project Based Learning Pada Mata Pelajaran Instalasi. Jurnal Imiah Pendidikan Dan Pembelajaran, 3, 306-315. https: //ejournal.undiksha.ac.id/index.php/JIPP/article/viewFile/21840/13513.

Lestari, W. (2021). Pengembangan Modul Pembelajaran Bahasa Inggris Berbasis Andragogi Pada Program Studi Pendidikan Biologi di Universitas Muhammadiyah Palembang A. Pendahuluan strategi pembelajaran yang harus diarahkan pada keefektifan mahasiswa, sedangkan pembelajaran ES. Jurnal Ilmiah Pendidikan, 2(1), 171-177. https://doi.org/10.51276/edu.v2i1.114.

Maghfiroh, Y., \& Hardini, A. T. A. (2021). Pengembangan Modul Pembelajaran Matematika Materi Pecahan Kelas V Sekolah Dasar. Jurnal Educatio FKIP UNMA, 7(2), 272-281. https://doi.org/10.31949/educatio.v7i2.997.

Muhamad Nova. (2017). Character Education In Indonesia EFL Classroom Implementation and Obstacles. Jurnal Pendidikan Karakter, 7(2). https://doi.org/10.21831/jpk.v7i2.13650.

Mukaromah, S. M. (2018). Pengembangan Modul IPA Braille Berbasis Integrasi Islam dan Sains. Inklusi, 5(2), 195. https://doi.org/10.14421/ijds.050203.

Muskania, R. T., Badariah, S., \& Mansur, M. (2019). Pembelajaran Tematik Menggunakan Media Video Scribe Pada Siswa Kelas IV Sekolah Dasar. Elementary: Islamic Teacher Journal, 7(1). 
https://doi.org/10.21043/elementary.v7i1.4927.

Nakayama, M, \& Yamamoto. (2007). Investigating the impact of learner characteristics on blended learning among Japanese Students. Proceedings of the International Conference on E-Learning, ICEL, 2006-Janua(3), 361-370. https://files.eric.ed.gov/fulltext/EJ1098825.pdf.

Neppala, P., Sherer, M. V., Larson, G., Bryant, A. K., Panjwani, N., Murphy, J. D., \& Gillespie, E. F. (2018). An interactive contouring module improves engagement and interest in radiation oncology among preclinical medical students: Results of a randomized trial. Practical Radiation Oncology, 8(4), e190-e198. https://doi.org/10.1016/j.prro.2018.01.001.

Nilawati, N., Rusdinal, R., \& Subandi, A. (2020). Development of an ICT-based Interactive Training Module in Improving Organizational Development Competencies for Elementary School Principals. International Conference on Elementary Education, 2(No1). http://proceedings.upi.edu/index.php/icee/article/view/743.

Novika Auliyana, S., Akbar, S., \& Yuniastuti. (2018). Penerapan Pembelajaran Tematik Terpadu di Sekolah Dasar. Jurnal Pendidikan: Teori, Penelitian, Dan Pengembangan, 3(12), 1572-1582. https://doi.org/10.17977/jptpp.v3i12.11796.

Nurohmah, A. N., \& Dewi, D. A. (2021). Penanaman Nilai Moral dan Karakter di Era Pandemi melalui Pendidikan dengan Mengimplementasikan Nilai-Nilai Pancasila. Journal of Education, Psychology and Counseling, 3(1), 119-128. https://ummaspul.e-journal.id/Edupsycouns/article/view/1305

Onde, M. L. ode, Aswat, H., Fitriani, \& Sari, E. R. (2020). Integrasi Penguatan Pendidikan Karakter (PPK) ERA 4.0 Pada Pembelajaran Berbasis Tematik Integratif Di Sekolah Dasar. Jurnal Basicedu, 4(2), 268-279. https://doi.org/10.31004/basicedu.v4i2.321.

Pane, A., \& Dasopang, M. D. (2017). Belajar dan Pembelajaran. FITRAH:Jurnal Kajian Ilmu-Ilmu Keislaman, 03(2). https://doi.org/10.24952/fitrah.v3i2.945.

Pitaloka, D. L., Dimyati, D., \& Edi, P. (2021). Peran Guru dalam Menanamkan Nilai Toleransi pada Anak Usia Dini di Indonesia. Jurnal Obsesi: Jurnal Pendidikan Anak Usia Dini, 5(2), 1696-1705. https://doi.org/10.31004/obsesi.v5i2.972.

Prayito. (2011). Pengembangan Perangkat Pembelajaran Matematika Humanistik Berbasis Konstruktivisme Berbantuan E-Learning Materi Segitiga Kelas VII. AKSIOMA Journal of Mathematics Education, 2(2). https://doi.org/https://doi.org/10.26877/aks.v2i2/Septembe.37.

Putra, K. W. B., Wirawan, I. M. A., \& Pradnyana, G. A. (2017). Pengembangan E-Modul Berbasis Model Pembelajaran Discovery Learning Pada Mata Pelajaran "Sistem Komputer " Untuk Siswa Kelas X Multimedia Smk Negeri 3 Singaraja. Jurnal Pendidikan Teknologi Dan Kejuruan, 14(1), 40-49. https://doi.org/10.23887/jptk.v14i1.9880.

Rahmawati, M., \& Harmanto. (2020). Pembentukan Nilai Karakter Toleransi dalam Pembelajaran Pendidikan Pancasila dan Kewarganegaraan Bagi Siswa Tunagrahita. Journal of Civics and Moral Studies, 5(1), 59-72. https://journal.unesa.ac.id/index.php/jcms/article/view/11881

Ramadhan, M. A., Handoyo, S. S., \& Alfarisi, M. (2020). Pengembangan bahan ajar fisika dasar berbasis emodul di pendidikan teknik bangunan universitas negeri jakarta. Jurnal Pendidikan Teknik Sipil, II(No. 2), 117-123. https://doi.org/10.21831/jpts.v2i2.36346

Ramdhani, S., Yuliastri, N. A., Sari, S. D., \& Hasriah, S. (2019). Penanaman Nilai-Nilai Karakter melalui Kegiatan Storytelling dengan Menggunakan Cerita Rakyat Sasak pada Anak Usia Dini. Jurnal Obsesi : Jurnal Pendidikan Anak Usia Dini, 3(1), 153. https://doi.org/10.31004/obsesi.v3i1.108.

Ramli, M. S., \& Tajudin, N. (2021). Analisis keperluan untuk membangunkan Modul Pembelajaran Berasaskan Challenge dalam Mempelajari Matematik bagi murid tingkatan 4. Jurnal Pendidikan Sains \& Matematik Malaysia, 11, 50-58. https://doi.org/10.37134/jpsmm.vol11.sp.5.2021.

Ricu Sidiq, \& Najuah. (2020). Pengembangan E-Modul Interaktif Berbasis Android pada Mata Kuliah Strategi Belajar Mengajar. Jurnal Pendidikan Sejarah, 9(1), 1-14. https://doi.org/10.21009/jps.091.01.

Rizki, A. (2018). Peningkatan Pembelajaran PKN Dengan Penerapan Metode Role-Playing Siswa Kelas II

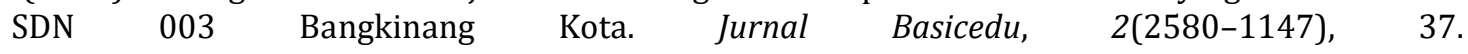
https://media.neliti.com/media/publications/278080-peningkatan-pembelajaran-pkn-denganpene-2358075c.pdf.

Sadia, W. (2013). Model Pendidikan Karakter Terintegrasi Pembelajaran Sains. JPI Jurnal Pendidikan Indonesia), 2(2), 209-220. https://doi.org/10.23887/jpi-undiksha.v2i2.2165.

Safitri, W. L., Darma, Y., \& Haryadi, R. (2021). Pengembangan Modul Pembelajaran dengan Metode Inkuiri terhadap Kemampuan Berpikir Kritis dalam Materi Segi Empatdan Segitiga Siswa SMP. Jurnal Numeracy, 8(1), 25-40. https://doi.org/10.46244/numeracy.v8i1.1333.

Sasmito, \& Mustadi. (2015). Developing learners' tematik-integrative worksheet based on character education for primary school students. Jurnal Pendidikan Karakter, 1, 7-8. 
https://journal.uny.ac.id/index.php/jpka/article/view/8613

Seruni, R., Munawaoh, S., Kurniadewi, F., \& Nurjayadi, M. (2019). Pengembangan Modul Elektronik (EModule) Biokimia Pada Materi Metabolisme Lipid Menggunakan Flip Pdf Professional. JTK (Jurnal Tadris Kimiya), 4(1), 48-56. https://doi.org/10.15575/jtk.v4i1.4672.

Setiawan, A. R. (2020). Pembelajaran Tematik Berorientasi Literasi Saintifik. Jurnal Basicedu, 3(2), 524532. https://doi.org/https://doi.org/10.31004/basicedu.v4i1.298.

Sirnayatin, T. A. (2017). Membangun Karakter Bangsa Melalui Pembelajaran Sejarah. SAP (Susunan Artikel Pendidikan), 1(3), 312-321. https://doi.org/10.30998/sap.v1i3.1171.

Solihudin JH, T. (2018). Pengembangan E-Modul Berbasis Web Untuk Meningkatkan Pencapaian Kompetensi Pengetahuan Fisika Pada Materi Listrik Statis Dan Dinamis Sma. WaPFi (Wahana Pendidikan Fisika), 3(2), 51. https://doi.org/10.17509/wapfi.v3i2.13731.

Suastika, I. K., \& Amaylyla. (2019). Pengembangan modul pembelajaran matematika dengan pendekatan

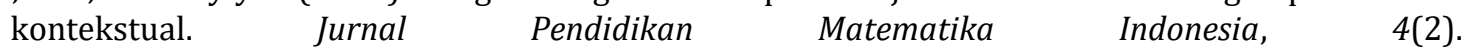
https://doi.org/https://dx.doi.org/10.26737/jpmi.v4i2.1230.

Sulistyaningrum, H., Kuntum, H., \& Ummatin, K. (2018). Effectiveness Of Problem Solving Of Solso And Locus Of Control Against Mathematics Learning Achievements Of High School Students. Jurnal $\begin{array}{lll}\text { Teladan, } \quad \text { Volume } & \text { 3(2), }\end{array}$ http://journal.unirow.ac.id/index.php/teladan/article/download/41/41/.

Susilowati, S., Sajidan, S., \& Ramli, M. (2018). Keefektifan perangkat pembelajaran berbasis inquiry lesson untuk meningkatkan keterampilan berpikir kritis siswa. Jurnal Penelitian Dan Evaluasi Pendidikan, 22(1), 49-60. https://doi.org/10.21831/pep.v22i1.17836.

Suwasono. (2013). Pengembangan E-Modul Online Elektronika Analog Pada Pendidikan Jarak Jauh. Teknologi Dan Kejuruan, 36(1), 51-62. https://doi.org/10.17977/tk.v36i1.4070.

Taqiya, Nuroso, \& Reffiane. (2019). Pengaruh Model Pembelajaran Terpadu Tipe Connected Berbantu Media Video Animasi. Mimbar PGSD Undiksha, 7(3), 289-295. https://doi.org/http://dx.doi.org/10.23887/jjpgsd.v7i3.19492.

Tegeh, I. M., \& Kirna, I. M. (2013). Pengembangan Bahan Ajar Metode Penelitian Pendidikan dengan ADDIE Model. Jurnal Pendidikan, 11(1), 16. https://doi.org/http://dx.doi.org/10.23887/ika.v11i1.1145.

Tien, T., \& Osman, K. (2012). Interactive multimedia module in the learning of electrochemistry :effects on students' understanding and motivation. 46, 1323-1327. https://doi.org/10.1016/j.sbspro.2012.05.295.

Torlakson, T. (2014). Innovate A Blueprint for Science, Technology, Engineering, and Mathematics in California Public Education. Californians Dedicated to Education Foundation, May, 52. https://www.cde.ca.gov/pd/ca/sc/documents/innovate.pdf

Wibowo, E. (2018). Pengembangan Bahan Ajar E-Modul Dengan Menggunakan Aplikasi Kvisoft Flipbook Maker. Universitas Islam Negeri (UIN).

Wibowo, E., \& Pratiwi, D. D. (2018). Pengembangan Bahan Ajar Menggunakan Aplikasi Kvisoft Flipbook Maker Materi Himpunan. Desimal: Jurnal Matematika, 1(2), 147. https://doi.org/10.24042/djm.v1i2.2279.

Winarno, W. W., Rusnaini, R., Muchtarom, M., Yuliandri, E., Rasyid, M. Al, \& Suryaningsih, A. (2020). Analisis Kesulitan Guru PPKn dalam Mengembangkan Materi Pembelajaran Bhinneka Tunggal Ika. Journal of Moral and Civic Education, 4(2), 97-112. https://doi.org/10.24036/8851412422020510.

Witasari, O., \& Wiyani, N. A. (2020). Permainan Tradisional untuk Membentuk Karakter Anak Usia Dini. JECED: Journal of Early Childhood Education and Development, 2(1), 52-63. https://doi.org/10.15642/jeced.v2i1.567. 